\title{
Genetic diversity of Leishmania infantum field populations from Brazil
}

\author{
Marcela Segatto ${ }^{1,2}$, Lucas Secchim Ribeiro', ${ }^{1,2}$ Dorcas Lamounier Costa ${ }^{3}$, \\ Carlos Henrique Nery Costa ${ }^{3}$, Márcia Rosa de Oliveira ${ }^{4}$, Sílvio Fernando Guimarães Carvalho ${ }^{5}$, \\ Andréa Mara Macedo ${ }^{2}$, Helder Magno Silva Valadares ${ }^{2,6}$, Reynaldo Dietze ${ }^{1}$, \\ Cristiana Ferreira Alves de Brito7, Elenice Moreira Lemos ${ }^{1 /+}$
}

\author{
'Laboratório de Leishmanioses, Núcleo de Doenças Infecciosas, Universidade Federal do Espírito Santo, Vitória, ES, Brasil \\ ${ }^{2}$ Departamento de Bioquímica e Imunologia, Universidade Federal de Minas Gerais, Belo Horizonte, MG, Brasil \\ ${ }^{3}$ Instituto Natan Portella para Doenças Tropicais, Teresina, PI, Brasil ${ }^{4}$ Departamento de Biologia Celular, \\ Universidade Federal da Paraíba, João Pessoa, PB, Brasil ${ }^{5}$ Universidade Estadual de Montes Claros, Montes Claros, MG, Brasil \\ ${ }^{6}$ Universidade Federal de São João del-Rey, Divinópolis, MG, Brasil ' Instituto René Rachou-Fiocruz, Belo Horizonte, MG, Brasil
}

Leishmania infantum (syn. Leishmania chagasi) is the etiological agent of visceral leishmaniasis (VL) in Brazil. The epidemiology of VL is poorly understood. Therefore, a more detailed molecular characterization at an intraspecific level is certainly needed. Herein, three independent molecular methods, multilocus microsatellite typing (MLMT), random amplification of polymorphic DNA (RAPD) and simple sequence repeats-polymerase chain reaction (SSR-PCR), were used to evaluate the genetic diversity of $53 \mathrm{~L}$. infantum isolates from five different endemic areas in Brazil. Population structures were inferred by distance-based and Bayesian-based approaches. Eighteen very similar genotypes were detected by MLMT, most of them differed in only one locus and no correlation was found between MLMT profiles, geographical origin or the estimated population structure. However, complex profiles composed of 182 bands obtained by both RAPD and SSR-PCR assays gave different results. Unweighted pair group method with arithmetic mean trees built from these data revealed a high degree of homogeneity within isolates of $\mathrm{L}$. infantum. Interestingly, despite this genetic homogeneity, most of the isolates clustered according to their geographical origin.

Key words: Leishmania infantum - genetic diversity - MLMT - RAPD - SSR-PCR

Visceral leishmaniasis (VL) is a systemic disease caused by an intracellular protozoan belonging to the Leishmania donovani complex: L. donovani, Leishmania infantum and Leishmania chagasi (Lainson \& Shaw 1987), which display different geographical distributions. In Brazil, the etiological agent of VL is L. chagasi, recently found to be derived from European strains of $L$. infantum (Kuhls et al. 2011, Leblois et al. 2011).

Clinical and laboratory manifestations of VL are well characterized and include fever, paleness, gradual weight loss, splenomegaly, hypergammaglobulinaemia and pancytopenia. However, different clinical symptoms have been associated with the etiological agent species. Postkala-azar dermal leishmaniasis, a dermal complication following recovery from a VL infection, is caused by $L$. donovani. In Europe, L. infantum causes VL and also cutaneous leishmaniasis, whereas in Brazil, the latter clinical symptom associated with $L$. infantum is uncommon.

Brazilian VL has intriguing epidemiological data, such as patients showing severe disease that leads to death while others have no complications, the high incidence of the disease in the Northeast Region (which accounts for $65 \%$ of cases) and the fact that $41 \%$ of cases

+ Corresponding author: lemosem@ndi.ufes.br

Received 17 April 2011

Accepted 23 September 2011 are reported in children under five years of age (MS 2006). In this context, it raises the question of whether the variation in the pathogenicity of the parasite and clinical features of VL may be related to its genetic diversity. However, before addressing this question, it is important to analyse the genetic diversity of the parasite.

Many molecular methods have been developed to evaluate the genetic diversity of Leishmania parasites. These include the amplification of DNA sequences of the parasite by specific polymerase chain reaction (PCR), the random amplification of polymorphic DNA (RAPD) (Hide et al. 2001, Zemanova et al. 2004), simple sequence repeats-PCR (SSR-PCR) (Oliveira et al. 1997, de Oliveira et al. 2007), PCR of antigen-encoding genes (gp63 and $c p b$ ) followed by analysis of restriction fragment length polymorphism (RFLP) (Mauricio et al. 2001, Quispe-Tintaya et al. 2004), PCR-RFLP of kinetoplast DNA (kDNA) minicircles (Morales et al. 2001, Chicharro et al. 2002) and, more recently, multilocus microsatellite typing (MLMT) (Ochsenreither et al. 2006, Alam et al. 2009).

Using these different molecular approaches, many studies have been conducted to evaluate the variability of various species of Leishmania (Mauricio et al. 1999, Hide et al. 2001, Ishikawa et al. 2002, Ochsenreither et al. 2006, de Oliveira et al. 2007). These studies mainly aimed to detect polymorphisms between isolates from different species, as well as within isolates from the same species, but from different geographic areas. Recently, a study was conducted to evaluate the variability of 40 Brazilian L. infantum strains, but all of the isolates were obtained from the same region (Alonso et al. 2010). 
Therefore, considering the relevance of VL and the role that genetic polymorphisms play in the epidemiology of the disease, this study evaluated the genetic diversity of L. infantum isolates obtained from different endemic areas in Brazil, using three different molecular approaches: MLMT, RAPD and SSR-PCR.

\section{MATERIALS AND METHODS}

Parasite isolates - A total of 53 isolates were analysed: 49 were obtained from humans and four were obtained from dogs (Table I). Parasites were isolated from patients by bone marrow aspirates and from dogs by spleen biopsies. The samples were collected in different VL endemic areas of Brazil, including the states of Espírito Santo (ES), Maranhão (MA), Minas Gerais (MG), Paraíba (PB) and Piauí (PI) (Fig. 1). All stocks were identified as L. infantum by PCR-RFLP from the conserved region of the Leishmania kDNA minicircle, in accordance with Volpini et al. (2004). As reference strains, we included L. infantum (MHOM/BR/74/PP75), Leishmania amazonensis (MHOM/BR/73/M2269) and Leishmania braziliensis (MHOM/BR/75/M2903). This study was approved by the Ethical Committee of the Federal University of Espírito Santo (CEP-023/07).

Parasite culture and DNA preparation - The parasites were cultivated in liver infusion tryptose medium supplemented with $10 \%$ of heat inactivated foetal calf serum and grown at $24-26^{\circ} \mathrm{C}$ until the parasite concentration reached $\sim 10^{7}$ parasites $/ \mathrm{mL}$. At this phase, $1.0 \mathrm{~mL}$ of the promastigote culture was washed in phosphatebuffered saline ( $\mathrm{pH}$ 7.2) and DNA extraction was performed using the Wizard ${ }^{\mathrm{TM}}$ Genomic DNA Purification System (Promega, Madison, Wisconsin, USA), as recommended by the manufacturer.

Microsatellite typing - For microsatellite analyses, we amplified seven polymorphic loci previously described for the L. donovani complex Li22-35, Li23-41, Li45-24, Li71-33, Lm2TG, Lm4TA and TubCA (Ochsenreither et al. 2006). Each PCR was performed in a total volume of $15 \mu \mathrm{L}$ containing $250 \mu \mathrm{M}$ of each dNTP, 0.5 U Platinum Taq DNA Polymerase (Invitrogen, Carlsbad, CA, USA), 20 mMTris-HCl (pH 8.0), $50 \mathrm{mMKCl}$, $2.0 \mathrm{mM} \mathrm{MgCl}, 0.2 \mu \mathrm{M}$ of each primer and $3 \mathrm{ng}$ of DNA template. Amplifications were performed using a stepdown protocol (Hecker \& Roux 1996) modified for the amplification of $L$. infantum DNA, which consisted of an initial denaturation step at $94^{\circ} \mathrm{C}$ for $5 \mathrm{~min}$, annealing at $58^{\circ} \mathrm{C}$ for $30 \mathrm{~s}$, primer extension at $72^{\circ} \mathrm{C}$ for $1 \mathrm{~min}$ and a denaturation step at $94^{\circ} \mathrm{C}$ for $30 \mathrm{~s}$. After five cycles, the annealing temperature was decreased to $56^{\circ} \mathrm{C}$ and after an additional five cycles to $54^{\circ} \mathrm{C}$. At the final annealing temperature, the number of cycles was increased to 23 , followed by a final extension step at $72^{\circ} \mathrm{C}$ for $10 \mathrm{~min}$.

To determine the allele sizes, $0.8-3 \mu \mathrm{L}$ of the fluorescent PCR products were analysed in a $6 \%$ denaturing polyacrylamide gel in an Automatic Laser Fluorescent sequencer (GE Healthcare, Milwaukee, Wisconsin, USA) and compared with fluorescent DNA fragments of 50-500 bp using the AlleleLocator software (GE Healthcare, Milwaukee, Wisconsin, USA).
TABLE I

Leishmania infantum isolates used in this study
Laboratory
code

PP75

ES01

ES02

ES03

ES04

ES05

MG01

MG02

MG03

MG04

MG05

MG06

MG07

MG08

MG09

MG10

MG11

MG12

MG13

MG14

MG15

MG16

MG17

MG18

MG19

MG20

MA01

MA02

MA03

MA04

MA05

MA06

MA07

PB01

PB02

PB03

PB04

$\mathrm{C} 01$

$\mathrm{C} 02$

$\mathrm{C} 03$

$\mathrm{C} 04$

PI01

PI02

PI03

PI04

PI05

PI06

PI07

PI08

PI09

PI10

PI11

PI12

PI13
Geographic area (city - state)

ATCC

Pancas - ES

Pancas - ES

Pancas - ES

Brejetuba - ES

Pancas - ES

Francisco Sá - MG

São Francisco - MG

Montes Claros - MG

Montes Claros - MG

Montes Claros - MG

Pirapora - MG

Montes Claros - MG

Montes Claros - MG

Montes Claros - MG

Porteirinha - MG

Montes Claros - MG

Montes Claros - MG

São Francisco - MG Bocaiúva - MG

Montes Claros - MG

Bocaiúva - MG

Porteirinha - MG

Montes Claros - MG Catuni - MG

Montes Claros - MG

Paraibano - MA Codó - MA

Timon - MA Codó - MA Timon - MA Timon - MA Caxias - MA Itabaiana - PB Marcação - PB João Pessoa - PB

João Pessoa - PB

João Pessoa - PB

João Pessoa - PB

João Pessoa - PB

João Pessoa - PB

José de Freitas - PI

Valença do Piauí - PI Cabeceiras - PI

Valença do Piauí - PI

Valença do Piauí - PI

Nossa Senhora dos Remédios - PI Piripiri - PI Altos - PI

MHOM/BR/06/PI07 MHOM/BR/05/PI08 MHOM/BR/05/PI09

MHOM/BR/06/PI10

MHOM/BR/06/PI1

MHOM/BR/05/PI12

MHOM/BR/06/PI13
Nova Santa Rita - PI Teresina - PI

José de Freitas - PI

Lima Campos - PI

Santa Cruz dos Milagres - PI a: canine isolate; ATCC: American Type Culture Collection; ES: Espírito Santo; MA: Maranhão; MG: Minas Gerais; PB: Paraíba; PI: Piauí; WHO: World Health Organization. 


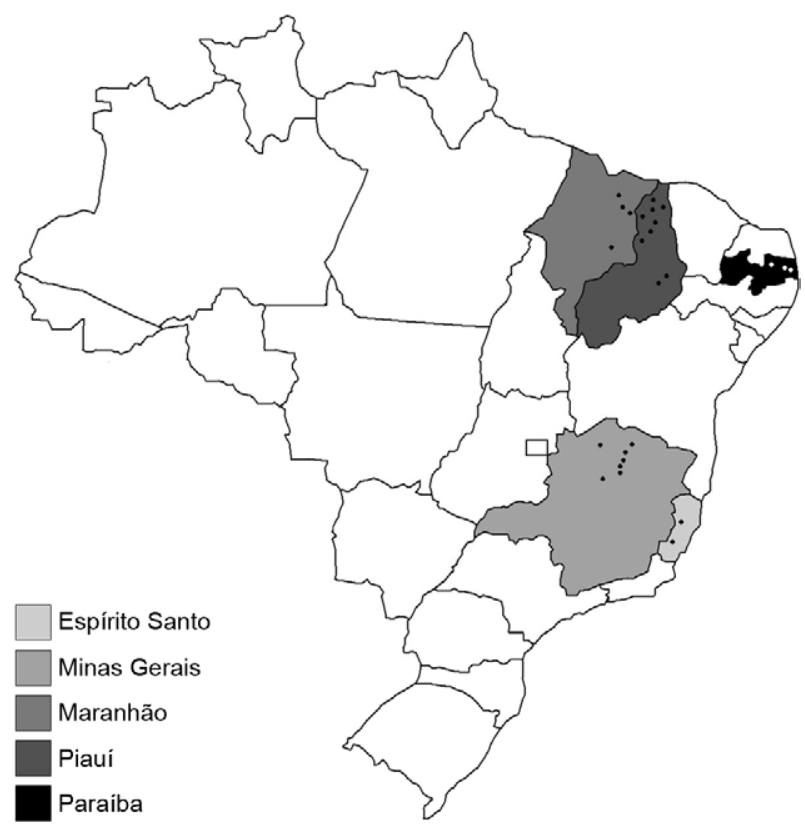

Fig. 1: map of Brazil and geographical distribution of the Brazilian Leishmania infantum isolates used in this study.

$R A P D$ - The RAPD procedure was performed essentially as described by Steindel et al. (1993). One nanogram of total DNA was amplified in a final volume of $25 \mu \mathrm{L}$ containing $1 \mathrm{U}$ of Taq DNA polymerase, $200 \mu \mathrm{M}$ of each dNTP, $10 \mathrm{mM}$ Tris- $\mathrm{HCl}(\mathrm{pH} 8.6), 50 \mathrm{mMKCl}$, $2 \mathrm{mM} \mathrm{MgCl}$ and $0.5 \mu \mathrm{M}$ of each primer. We selected the five primers showing the highest polymorphism in a previous report: A1, B4, B10, F10 and R15 (Hide et al. 2001). The amplification program consisted of an initial denaturation step at $95^{\circ} \mathrm{C}$ for $5 \mathrm{~min}$, followed by two cycles of denaturation at $95^{\circ} \mathrm{C}$ for $30 \mathrm{~s}$, annealing at $30^{\circ} \mathrm{C}$ for $2 \mathrm{~min}$ and extension at $72^{\circ} \mathrm{C}$ for $1 \mathrm{~min}$; this was followed by 30 cycles in which the annealing step temperature was increased to $40^{\circ} \mathrm{C}$. The final extension was for $5 \mathrm{~min}$ at $72^{\circ} \mathrm{C}$. Amplification products were analysed on $6 \%$ polyacrylamide gels after ethidium bromide staining. PCRs were repeated at least twice and only the consistent bands present in both gels were taken into account to build a reproducible profile of each isolate. The reproducibility was assessed using different concentrations of DNA obtained from different isolates, including the reference strain $L$. infantum (MHOM/BR/74/PP75). Every step was performed under strict and standardized conditions, including the enzyme and primer source and high-quality DNA at an adequate concentration.

SSR-PCR - The SSR-PCR amplification procedure was carried out as described by Oliveira et al. (1997). Each reaction was performed in a final volume of 10 $\mu \mathrm{L}$, containing $10 \mathrm{mM}$ Tris- $\mathrm{HCl}(\mathrm{pH} 8.6), 50 \mathrm{mM} \mathrm{KCl}$, $1.5 \mathrm{mM} \mathrm{MgCl}, 200 \mu \mathrm{M}$ of dNTPs, $2 \%$ formamide (v/v), $2.5 \mu \mathrm{M}$ of the primer (CA) ${ }_{8} \mathrm{RY}$ (Zietkiewicz et al. 1994), $1 \mathrm{U}$ of Taq DNA polymerase and $1 \mathrm{ng}$ of DNA. The amplification cycles consisted of an initial denaturation step at $94^{\circ} \mathrm{C}$ for $3 \mathrm{~min}$, followed by 26 cycles at $94^{\circ} \mathrm{C}$ for $30 \mathrm{~s}, 52^{\circ} \mathrm{C}$ for $45 \mathrm{~s}$ and $72^{\circ} \mathrm{C}$ for $1 \mathrm{~min}$. The final extension was done at $72^{\circ} \mathrm{C}$ for $7 \mathrm{~min}$. The amplification products were analysed on $6 \%$ polyacrylamide gels after ethidium bromide staining. PCR reactions were performed at least twice and amplifications were carried out on different days.

Data analysis - The multilocus microsatellite genotype data, consisting of the allele sizes or repeat numbers, were analysed by two different approaches: a Bayesian model-based clustering method using STRUCTURE software (Pritchard et al. 2000) and a distancebased method. For inferring population structure, the admixture model was assumed, which correlated allele frequencies among populations, independent of a particular mutation model. For each isolate, the fraction of its genotype that belongs to each population is measured and then genetic clusters are constructed from a collection of individual genotypes. Markov chain Monte Carlo searches consisted of a burn-in length of 50,000 iterations followed by a run of 250,000 replications for each setting of $K$. The complete set of individual isolates was divided into $K$ sub-populations, with $K$ ranging from 1-10 with 10 replicate runs of each. The appropriate number of populations in our sample test was determined by comparison of the log-likelihood values for $K$ 1-10 and the calculation of $\Delta K$ (Evanno et al. 2005). The intra-population diversity was measured using the statistic expected heterozygosity $\left(H_{\mathrm{E}}\right)$, as implemented in Arlequin 3.5 software (Excoffier et al. 2005).

Genetic distances D1 (average square distance), which follows the stepwise mutation model, were calculated for the repeat numbers within each microsatellite locus by using MICROSAT software (Stanford University Press, Stanford, CA). A tree based on these distances was constructed by the algorithm of the unweighted pair group method with arithmetic averages (UPGMA) using PHYLIP 3.67 package version 3.5. (University of Washington, Seattle, USA) and visualized with TreeView1.6.6 (Roderic 1996).

The band patterns obtained for each isolate resulting from RAPD and SSR-PCR procedures were scored by eye. In order to guarantee the quality control of inter-gel comparisons, the gels were aligned using the standard molecular weight marker and the profile of reference strain PP75, included in every PCR reaction and electrophoresis. Only well-defined bands were used to construct a binary table. Each amplification band was numbered and scored as present (1) or absent (0) and for each isolate genetic distances among them were calculated using the Nei coefficient (Nei 1978). A phylogenetic tree was constructed based on the genetic distance matrices obtained through UPGMA using Treecon software program version 1.3b (Van de Peer \& De Wachter 1994). The robustness of the internal branches was tested by bootstrap analysis from 1,000 replicates.

RAPD and SSR-PCR amplicons were analysed as dominant markers. To estimate genetic diversity from these data, a Hardy-Weinberg equilibrium was assumed among the populations and the allele frequencies were calculated based on the frequencies of the null alleles. A locus was considered polymorphic when a specific band present at least in one isolate was not observed in 
all other strains. $H_{\mathrm{E}}$ and percentage of polymorphic loci were estimated using the Tools for Population Genetic Analyses program version 1.3 (Department of Biological Sciences, Flagstagg, AZ, USA).

\section{RESULTS}

The analysis of data obtained by the microsatellite assay showed that most of the isolates had profiles that differed from each other by only one locus. For the seven analysed microsatellite loci, the number of different alleles detected ranged from 1-4 (Table II). The most polymorphic microsatellite locus was Lm4TA with four alleles. In contrast, the TubCA locus was monomorphic. The Li23-41 marker showed two alleles, but one was exclusively found in the canine isolate $\mathrm{C} 02$. Among the 51 Brazilian isolates evaluated, 18 different genotypes (multilocus microsatellite profiles) could be detected and they were closely related to one another. Most of the isolates had homozygous profiles for the seven loci tested, whereas eleven isolates showed heterozygosis in one locus (Table II). Three or more peaks, suggestive of aneuploidy or a mixture of heterozygous strains, were not observed. None of the seven microsatellite markers used here for the $L$. donovani complex were able to amplify the L. braziliensis strain and only two of them (Lm4TA and TubCA) amplified the $L$. amazonensis reference strain. However, the allele sizes were not compatible with those obtained from L. infantum isolates (data not shown). MLMT profiles were used to calculate genetic distances and to construct a UPGMA tree. As shown in Fig. 2A, no correlation was found between MLMT profiles, geographical origin or the host of isolates (human vs. canine).
Measures of genetic diversity within each population were low (Table III). The mean number of alleles per locus ranged from 1.0-1.7. The percentage of polymorphic loci was low for all populations. The $H_{\mathrm{E}}$, representing the probability of an individual to be heterozygous over the loci tested, varied between 0.097-0.193, with an exception for ES isolates $\left(H_{\mathrm{e}}=0.355\right)$. One in five ES isolates had an allelic variant for the Li22-35 locus.

Based on the data from seven microsatellite loci, an estimative population structure for Brazilian L. infantum was inferred from the STRUCTURE software, which indicated the existence of five ancestral populations. However, these genetic groups did not correlate with the geographical distribution of the isolates.

More interesting results were obtained with the RAPD and SSR-PCR techniques. Our results showed that both techniques were able to generate complex band patterns. However, these profiles were very similar regardless the approach used demonstrating the genetic homogeneity amongst the $L$. infantum isolates (Supplementary data). The RAPD amplifications of all isolates resulted in reproducible patterns, each primer giving characteristic and distinct band profiles. A total of 144 bands were analysed, with molecular weight varying from 400-1,200 bp. Isolate MG03 did not amplify with the $\mathrm{A} 1$ and $\mathrm{B} 10$ primers, even after several PCR assays.

The SSR-PCR approach yielded 38 reproducible bands (ranging from 400-1,200 bp). Fifty out of $53 \mathrm{~L}$. infantum isolates showed amplified products with the primer $(\mathrm{CA})_{8} \mathrm{RY}$. Multiple attempts to isolate DNA and amplify SSR from isolates MG05, PI13 and ES05 were

TABLE II

Multilocus microsatellite typing genotypes of the Brazilian Leishmania infantum isolates based on the number of repeats of the microsatellite markers

\begin{tabular}{|c|c|c|c|c|c|c|c|c|}
\hline \multirow[b]{2}{*}{ Genotype } & \multirow{2}{*}{$\begin{array}{l}\text { Isolates } \\
\text { (n) }\end{array}$} & \multicolumn{7}{|c|}{$\begin{array}{l}\text { Repeat units } \\
\text { (n) }\end{array}$} \\
\hline & & Li22-35 & Li23-41 & Li45-24 & Li71-33 & Lm2TG & Lm4TA & TubCA \\
\hline 1 & 13 & 16 & 18 & 14 & 12 & 26 & 13 & 8 \\
\hline 2 & 2 & 16 & 18 & 14 & 12 & 26 & $12 / 13$ & 8 \\
\hline 3 & 2 & 16 & 18 & 14 & 12 & 26 & $13 / 14$ & 8 \\
\hline 4 & 3 & 16 & 18 & 14 & 12 & 26 & 14 & 8 \\
\hline 5 & 1 & 16 & 18 & $14 / 15$ & 12 & 26 & 13 & 8 \\
\hline 6 & 3 & 16 & 18 & 15 & 12 & 26 & 13 & 8 \\
\hline 7 & 1 & 16 & 18 & 15 & $10 / 12$ & 27 & 13 & 8 \\
\hline 8 & 3 & 16 & 18 & 15 & 12 & 27 & 13 & 8 \\
\hline 9 & 1 & 16 & 18 & 14 & $11 / 12$ & 27 & 13 & 8 \\
\hline 10 & 1 & 16 & 18 & 14 & 12 & 27 & $13 / 14$ & 8 \\
\hline 11 & 11 & 16 & 18 & 14 & 12 & 27 & 13 & 8 \\
\hline 12 & 1 & 16 & 18 & $14 / 18$ & 12 & 26 & 13 & 8 \\
\hline 13 & 1 & 16 & 18 & 14 & 12 & 25 & 13 & 8 \\
\hline 14 & 1 & 16 & 18 & 15 & 12 & 25 & 13 & 8 \\
\hline 15 & 1 & 16 & 18 & 15 & $10 / 12$ & 26 & 13 & 8 \\
\hline 16 & 4 & 19 & 18 & 14 & 12 & 26 & 13 & 8 \\
\hline 17 & 1 & 16 & 18 & 14 & 12 & 25 & 11 & 8 \\
\hline 18 & 1 & 16 & 17 & 14 & 12 & 25 & $11 / 14$ & 8 \\
\hline Alleles (n) & & 2 & 2 & 3 & 3 & 3 & 4 & 1 \\
\hline
\end{tabular}


unsuccessful. However, unlike RAPD, identical profiles were generated for some of the different isolates evaluated. For both methodologies different profiles were generated for L. amazonensis, L. braziliensis and L. infantum (data not shown).

The trees constructed based on RAPD and SSR-PCR data are shown in Fig. 2B, C, respectively. A geographical structure was observed in the RAPD tree: $12 / 13 \mathrm{PI}$ isolates and 7/7 MA isolates were found in the same branch, isolates from ES were grouped with one isolate from $\mathrm{MG}$ (MG20), 18/19 MG isolates were grouped together in two branches and $7 / 8$ isolates from PB were clustered together. The results obtained by SSR-PCR also showed the existence of clusters composed of neighbouring populations. When a tree was built by combining the RAPD and SSRPCR data, four clusters were evident in which the isolates were grouped according to their geographic origin (Fig. 2D). Isolates from ES were grouped into a specific branch, within a major cluster composed of isolates from MG. Isolates from MA and PI were clustered together in a single branch without a clear distinction between them. $\mathrm{PB}$ isolates were clustered together in a fourth branch. We did not observe any specific clusters in relation to the host, as both human and canine isolates were found in the same cluster. In general, the UPGMA trees revealed a small genetic distance detected between the isolates.

Descriptive statistics of RAPD and SSR-PCR are shown in Table IV. The $H_{\mathrm{E}}$ varied between 0.121-0.222. The percentage of polymorphic loci ranged from 68.42 (SSR-PCR marker) to 86.96 (RAPD primer A1), with an average of 78.16 for all populations. According to this last parameter, RAPD assays were more discriminative than the SSR-PCR assay.

\section{DISCUSSION}

In this study we analysed the genetic polymorphisms of $L$. infantum isolates from different endemic areas of Brazil via MLMT, RAPD and SSR-PCR strategies. The UPGMA tree built from both RAPD and SSR-PCR data showed clustering of the isolates according to their geographical origin, with one cluster including isolates from $\mathrm{MA}$ and PI, a second cluster including isolates from MG and ES, which are neighbouring states, and a third cluster including only isolates from PB.

In accordance with our results, previous studies have demonstrated geographic structuring of Leishmania populations using different molecular markers. Cupolillo et al. (2003) used PCR-RFLP analysis for L. braziliensis and showed that most of the genotypes were associated with specific geographic areas. These results corroborate data from other studies, which demonstrated that DNA fingerprinting and RAPD analysis could separate strains of $L$. braziliensis and $L$. donovani on the basis of their geographic origin (Gomes et al. 1995, Zemanova et al. 2004). In the Mediterranean region, the distribution of L. infantum strains from southern Spain, characterized by RAPD analysis, was also found to be related to their geographic origin (Toledo et al. 2002). Similar results were observed by Guerbouj et al. (2001) when strains from southern France were analysed on the basis of chromosomal size. On the other hand, many authors did not find an association between isolate variability and their geographic distribution (Cortes et al. 2006, de Oliveira et al. 2007, Seridi et al. 2008). The same result was found in our study using MLMT analysis.

MLMT analysis showed 18 different genotypes, but most of the isolates shared an identical profile or differed only by one locus. According to the microsatellite typing, L. infantum from Brazil is a homogeneous species and the geographic correlation observed for RAPD and SSR-PCR was not detected. These different results can be attributed to the fact that we evaluated only seven loci for the microsatellite assay vs. 182 bands analysed for RAPD and SSR-PCR analyses.

Even though many studies have demonstrated that highly polymorphic microsatellite markers are useful for strain typing and population genetic studies in the $L$. donovani complex (Ochsenreither et al. 2006, Kuhls et al. 2007), this is not the first time that MLMT reveals high genetic homogeneity within a Leishmania species (Alam et al. 2009, Alonso et al. 2010). Because this method was unable to discriminate between different $L$. infantum isolates, it suggests that this methodology is not suitable for epidemiological studies of closely related Leishmania strains. Nevertheless, high-resolution electrophoresis is required and a set of polymorphic markers has to be analysed to achieve the highest discrimination amongst strains, which dramatically increases the cost of the assay.

Although the L. infantum isolates have been grouped according to their geographical origin using RAPD and SSR-PCR analyses, their genetic profiles were similar, suggesting that parasite populations of different regions from Brazil are homogenous. This similarity was supported by the low genetic distance detected between the isolates and the low estimated heterozygosity rates in the populations studied.

Despite the homogeneity detected in L. infantum, each isolate had a unique RAPD profile. In contrast to our results, the study performed by Alonso et al. (2010) using kDNA PCR-RFLP methodology demonstrated that more than $60 \%$ of the L. infantum isolates (26 of 40) showed an identical genetic profile. These authors attributed the observed homogeneity to the maintenance of the parasites in culture, which might select one or a few parasite lineages and for this reason, the genetic variability could be underestimated. However, in our study, all isolates were also obtained by culture. Therefore, it seems that RAPD analysis provided greater discriminatory power than did kDNA PCR-RFLP.

One explanation for the geographic structuring and low variability found for L. infantum in Brazil could be the recent introduction of this species to the New World (Mauricio et al. 1999, Kuhls et al. 2011). Another reason could be the fact that the transmission of this species in Brazil is associated with one major vector, Lutzomyia longipalpis (Lainson \& Rangel 2005) and that the degree of variability of Leishmania species has been related to the number of vectors and/or animal reservoir involved in the transmission of these parasites (Cupolillo et al. 2003).

The reproductive mode of a species can also affect its genetic polymorphisms. In the case of Leishmania, 
A

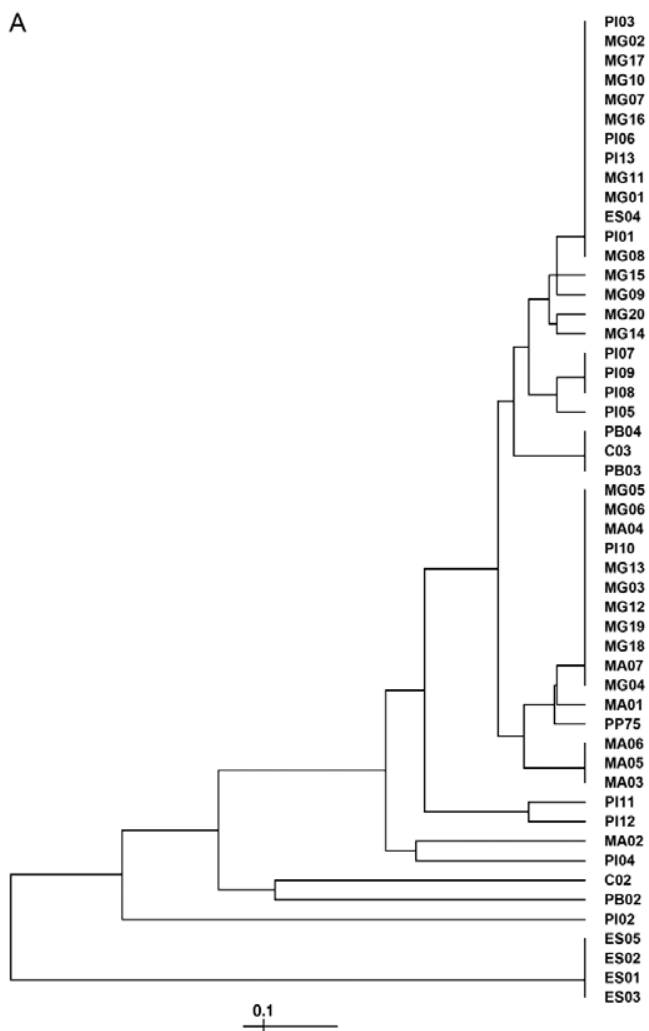

C

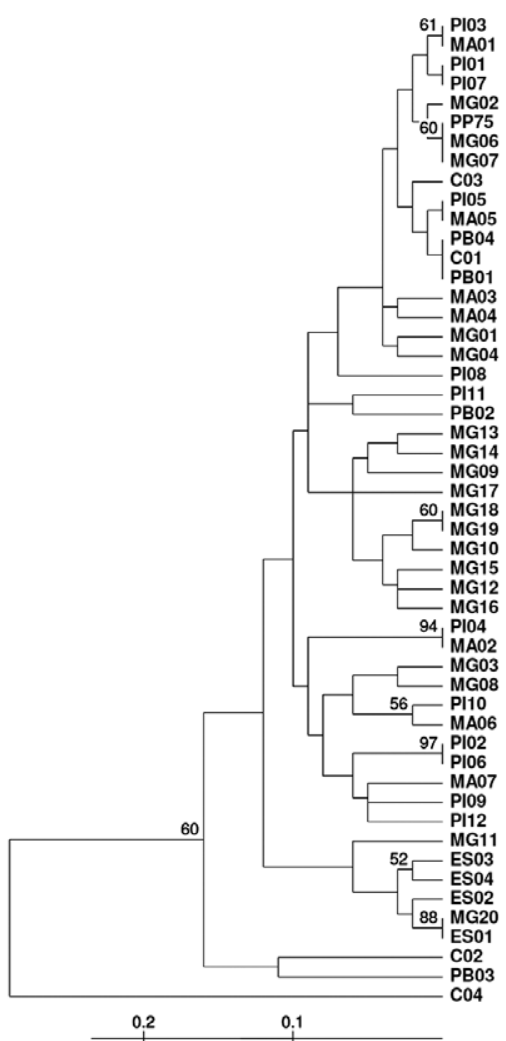

B

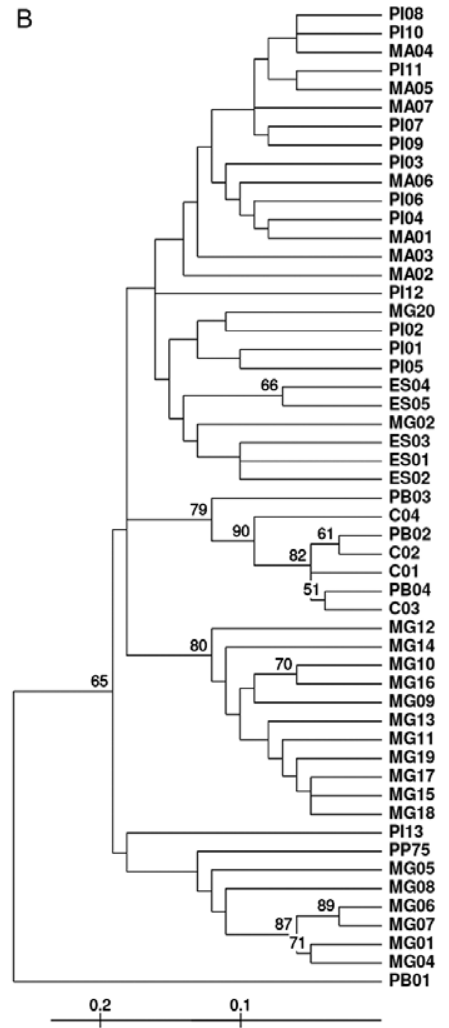

D

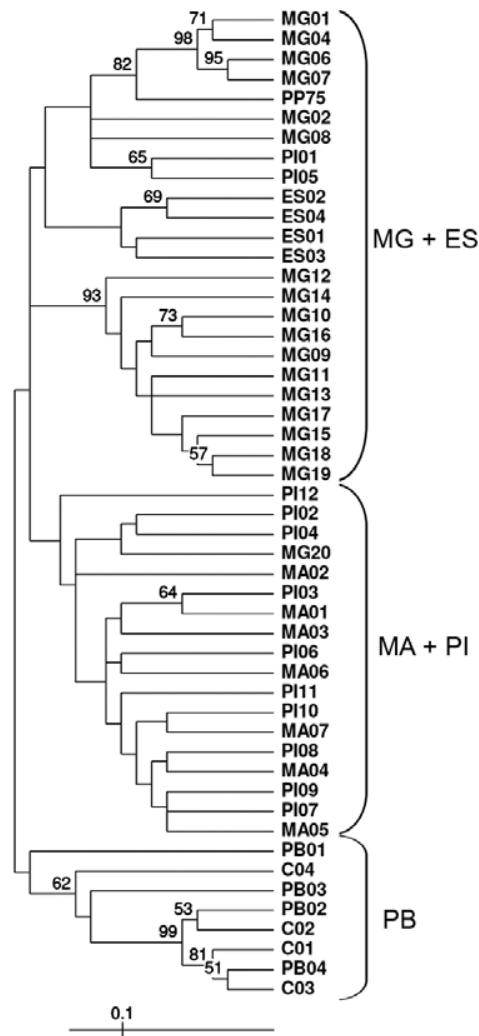

Fig. 2: unweighted pair group method with arithmetic mean tree of Leishmania infantum isolates built-up from data of multilocus microsatellite typing (A), random amplification of polymorphic DNA (RAPD) (B), simple sequence repeats-polymerase chain reaction (SSR-PCR) (C) [dogs strains from Paraíba (PB)] and RAPD and SSR-PCR together (D). Bootstraps values above 50 are indicated. PP75: L. infantum reference strain (MHOM/BR/74/PP75). ES: Espírito Santo; MA: Maranhão; MG: Minas Gerais; PI: Piauí. 
TABLE III

Measures of genetic diversity for the five Leishmania infantum populations studied according to multilocus microsatellite typing data

\begin{tabular}{lcccc}
\hline Population & $\begin{array}{c}\text { Isolates } \\
\text { (n) }\end{array}$ & $\begin{array}{c}\text { Proportion of } \\
\text { polymorphic loci }\end{array}$ & $\begin{array}{c}\text { Mean number of } \\
\text { alleles }\end{array}$ & $H_{\mathrm{E}} \pm \mathrm{SD}$ \\
\hline Espírito Santo & 5 & 0.143 & 1.142 & $0.355 \pm 0.000$ \\
Maranhão & 7 & 0.428 & 1.429 & $0.116 \pm 0.193$ \\
Minas Gerais & 20 & 0.258 & 1.429 & $0.097 \pm 0.187$ \\
Paraíba & 5 & 0.428 & 1.429 & $0.193 \pm 0.247$ \\
Piauí & 13 & 0.428 & 1.714 & $0.145 \pm 0.229$ \\
Mean & - & 0.343 & 1.400 & $0.181 \pm 0.171$ \\
\hline
\end{tabular}

$H_{\mathrm{E}}$ : expected heterozygosity; SD: standard deviation.

\section{TABLE IV}

Characteristics of the random amplification of polymorphic DNA and simple sequence repeats-polymerase chain reaction markers used and measures of genetic diversity for the five Leishmania infantum populations studied according to their data

\begin{tabular}{|c|c|c|c|c|c|c|c|c|}
\hline \multirow[b]{2}{*}{ Primers } & \multirow{2}{*}{$\begin{array}{l}\text { Number of analyzed bands } \\
\qquad(\mathrm{n}=182)\end{array}$} & \multirow{2}{*}{$\begin{array}{l}\text { Polymorphic loci } \\
(\%)\end{array}$} & \multicolumn{6}{|c|}{ Expected heterozygosity } \\
\hline & & & MG & PI & ES & $\mathrm{PB}$ & MA & Mean per locus \\
\hline A1 & 23 & 86.956 & 0.182 & 0.252 & 0.142 & 0.142 & 0.193 & 0.300 \\
\hline B4 & 26 & 84.615 & 0.292 & 0.244 & 0.093 & 0.103 & 0.116 & 0.287 \\
\hline B10 & 30 & 73.333 & 0.225 & 0.218 & 0.188 & 0.107 & 0.191 & 0.311 \\
\hline F10 & 26 & 84.615 & 0.286 & 0.184 & 0.135 & 0.144 & 0.155 & 0.331 \\
\hline $\mathrm{R} 15$ & 38 & 71.052 & 0.200 & 0.185 & 0.179 & 0.073 & 0.085 & 0.269 \\
\hline$(\mathrm{CA})_{8} \mathrm{RY}$ & 38 & 68.421 & 0.149 & 0.179 & 0.037 & 0.159 & 0.127 & 0.255 \\
\hline Mean & 30.333 & 78.165 & 0.222 & 0.210 & 0.129 & 0.121 & 0.144 & - \\
\hline \multicolumn{3}{|c|}{ Polymorphic loci within each population (\%) } & 58.69 & 58.13 & 30.32 & 28.90 & 37.13 & - \\
\hline
\end{tabular}

ES: Espírito Santo; MA: Maranhão; MG: Minas Gerais; PB: Paraíba; PI: Piauí.

reproduction has often been assumed to be strictly clonal, but this remains undetermined. Herein, we found a substantial heterozygote deficiency amongst the isolates studied and positive values were found for the inbreeding coefficient per microsatellite locus (data not shown), which could indicate high levels of inbreeding. These observations are inconsistent with a predominantly clonal mode of reproduction, which implies excess heterozygosity (Meselson effect). Moreover, as there is small genetic heterogeneity between populations within regions and no evidence of a strong population structure, this high number of homozygotes cannot be explained as the result of a population subdivision (Wahlund effect). A working hypothesis for these findings is that parasites alternate clonal and sexual reproduction with recombination events between individuals of similar genotypes (Kelly et al. 1991, Butlin 2002, Ravel et al. 2006, Nolder et al. 2007). Recently, it was reported that the invertebrate stages of Leishmania are capable of having a sexual cycle consistent with a meiotic process (Akopyants et al. 2009). However, the mechanism of recombination, at what frequency it occurs and whether it occurs in the mammalian host, remains to be addressed.
Our results also demonstrate that $L$. infantum isolates from human and dogs have the same profile, although we have only analysed a small number of isolates from dogs. These findings are in agreement with Chicharro et al. (2002) who worked with RAPD and intergenic ribosomal typing and could not discriminate amongst human and dog strains from the island of Majorca. Because the domestic dog has been incriminated as the main reservoir of VL, the fact that a strain isolated from humans displays a similar pattern to that of a canine stock fits well with the zoonotic cycle of L. infantum (MS 2006).

In conclusion, our results demonstrate that although the Brazilian L. infantum isolates are genetically homogeneous, there is a correlation between the isolates and their geographic origin. However, the development of methods with higher discriminatory power is still necessary to enhance our understanding of the molecular epidemiology of VL in Brazil.

\section{REFERENCES}

Akopyants NS, Kimblin N, Secundino N, Patrick R, Peters N, Lawyer P, Dobson DE, Beverley SM, Sacks DL 2009. Demonstration of genetic exchange during cyclical development of Leishmania in the sand fly vector. Science 324: 265-268. 
Alam MZ, Kuhls K, Schweynoch C, Sundar S, Rijal S, Shamsuzzaman AK, Raju BV, Salotra P, Dujardin JC, Schonian G 2009. Multilocus microsatellite typing (MLMT) reveals genetic homogeneity of Leishmania donovani strains in the Indian subcontinent. Infect Genet Evol 9: 24-31.

Alonso DP, Costa DL, de Mendonca IL, Costa CH, Ribolla PE 2010. Heterogeneity of Leishmania infantum chagasi kinetoplast DNA in Teresina (Brazil). Am J Trop Med Hyg 8: 819-821.

Butlin R 2002. Evolution of sex: the costs and benefits of sex - new insights from old asexual lineages. Nat Ver Genet 3: 311-317.

Chicharro C, Morales MA, Serra T, Ares M, Salas A, Alvar J 2002. Molecular epidemiology of Leishmania infantum on the island of Majorca: a comparison of phenotypic and genotypic tools. Trans R Soc Trop Med Hyg 96: 93-99.

Cortes S, Mauricio I, Almeida A, Cristovão JM, Pratlong F, Dedet JP, Campino L 2006. Application of kDNA as a molecular marker to analyse Leishmania infantum diversity in Portugal. Parasitol Int 55: 277-283.

Cupolillo E, Brahim LR, Toaldo CB, de Oliveira-Neto MP, de Brito ME, Falqueto A, de Farias Naiff M, Grimaldi G Jr 2003. Genetic polymorphism and molecular epidemiology of Leishmania ( $\mathrm{Vi-}$ annia) braziliensis from different hosts and geographic areas in Brazil. J Clin Microbiol 41: 3126-3132.

de Oliveira JP, Fernandes F, Cruz AK, Trombela V, Monteiro E, Camargo AA, Barral A, de Oliveira CI 2007. Genetic diversity of Leishmania amazonensis strains isolated in northeastern Brazil as revealed by DNA sequencing, PCR-based analyses and molecular karyotyping. Kinetoplastid Biol Dis 6: 5.

Evanno G, Regnaut S, Goudet J 2005. Detecting the number of clusters of individuals using the software STRUCTURE: a simulation study. Mol Ecol 14: 2611-2620.

Excoffier L, Laval G, Schneider S 2005. Arlequin (version 3.0): an integrated software package for population genetics data analysis. Evol Bioinform Online 1: 47-50.

Gomes RF, Macedo AM, Pena SD, Melo MN 1995. Leishmania (Viannia) braziliensis: genetic relationships between strains isolated from different areas of Brazil as revealed by DNA fingerprinting and RAPD. Exp Parasitol 80: 681-687.

Guerbouj S, Victoir K, Guizani I, Seridi N, Nuwayri-Salti N, Belkaid M, Ismail RB, Le Ray D, Dujardin JC 2001. Gp63 gene polymorphism and population structure of Leishmania donovani complex: influence of the host selection pressure? Parasitology 122: 25-35.

Hecker KH, Roux KH 1996. High and low annealing temperatures increase both specificity and yield in touchdown and stepdown PCR. Biotechniques 20: 478-485.

Hide M, Banuls AL, Tibayrenc M 2001. Genetic heterogeneity and phylogenetic status of Leishmania (Leishmania) infantum zymodeme MON-1: epidemiological implications. Parasitology 123: 425-432.

Ishikawa EA, Silveira FT, Magalhães AL, Guerra Jr RB, Melo MN, Gomes R, Silveira TG, Shaw JJ 2002. Genetic variation in populations of Leishmania species in Brazil. Trans $R$ Soc Trop Med Hyg 96: 111-121.

Kelly JM, Law JM, Chapman CJ, Van Eys GJ, Evans DA 1991. Evidence of genetic recombination in Leishmania. Mol Biochem Parasitol 46: 253-263.

Kuhls K, Alam MZ, Cupolillo E, Ferreira GE, Mauricio IL, Oddone R, Feliciangeli MD, Wirth T, Miles MA, Schönian G 2011. Comparative microsatellite typing of New World Leishmania infantum reveals low heterogeneity among populations and its recent Old World origin. PLoS Negl Trop Dis 5: e1155.
Kuhls K, Keilonat L, Ochsenreither S, Schaar M, Schweynoch C, Presber W, Schonian G 2007. Multilocus microsatellite typing (MLMT) reveals genetically isolated populations between and within the main endemic regions of visceral leishmaniasis. Microbes Infect 9: 334-343.

Lainson R, Rangel EF 2005. Lutzomyia longipalpis and the eco-epidemiology of American visceral leishmaniasis, with particular reference to Brazil - A Review. Mem Inst Oswaldo Cruz 100: 811-827.

Lainson R, Shaw JJ 1987. Evolution, classification and geographical distribution. In W Peters, R Killick-Kendrick, The leishmaniasis in biology and medicine, Academic Press Inc, London, p. 1-120.

Leblois R, Kuhls K, François O, Schönian G, Wirth T 2011. Guns, germs and dogs: on the origin of Leishmania chagasi. Infect Genet Evol 11: 1091-1095.

Mauricio IL, Gaunt MW, Stothard JR, Miles MA 2001. Genetic typing and phylogeny of the Leishmania donovani complex by restriction analysis of PCR amplified gp63 intergenic regions. Parasitology 122: 393-403.

Mauricio IL, Howard MK, Stothard JR, Miles MA 1999. Genomic diversity in the Leishmania donovani complex. Parasitology 119: $237-246$.

Morales MA, Chicharro C, Ares M, Cañavate C, Barker DC, Alvar J 2001. Molecular tracking of infections by Leishmania infantum. Trans R Soc Trop Med Hyg 95: 104-107.

MS - Ministério da Saúde Brasil 2006. Manual de vigilância e controle da leishmaniose visceral, 3rd ed., MS, Brasília, 120 pp.

Nei M 1978. Estimation of average heterozygosity and genetic distance from a small number of individuals. Genetics 89: 583-590.

Nolder D, Roncal N, Davies CR, Llanos-Cuentas A, Miles MA 2007. Multiple hybrid genotypes of Leishmania (viannia) in a focus of mucocutaneous leishmaniasis. Am J Trop Med Hyg 76: 573-578.

Ochsenreither S, Kuhls K, Schaar M, Presber W, Schonian G 2006. Multilocus microsatellite typing as a new tool for discrimination of Leishmania infantum MON-1 strains. J Clin Microbiol 44: 495-503.

Oliveira RP, Macedo AM, Chiari E, Pena SD 1997. An alternative approach to evaluating the intraspecific genetic variability of parasites. Parasitol Today 13: 196-200.

Pritchard JK, Stephens M, Donnelly P 2000. Inference of population structure using multilocus genotype data. Genetics 155: 945-959.

Quispe-Tintaya KW, Ying X, Dedet JP, Rijal S, De Bolle X, Dujardin JC 2004. Antigen genes for molecular epidemiology of leishmaniasis: polymorphism of cysteine proteinase $B$ and surface metalloprotease glycoprotein 63 in the Leishmania donovani complex. J Infect Dis 189: 1035-1043.

Ravel C, Cortes S, Pratlong F, Morio F, Dedet JP, Campino L 2006. First report of genetic hybrids between two very divergent Leishmania species: Leishmania infantum and Leishmania major. Int $J$ Parasitol 36: 1383-1388.

Roderic DM 1996. TREEVIEW: an application to display phylogenetic trees on personal computers. Comput Appl Biosci 12: 357-358.

Seridi N, Belkaid M, Quispe-Tintaya W, Zidane C, Dujardin JC 2008. Application of PCR-RFLP for the exploration of the molecular diversity of Leishmania infantum in Algeria. Trans $R$ Soc Trop Med Hyg 102: 556-563.

Steindel M, Dias Neto E, de Menezes CL, Romanha AJ, Simpson AJ 1993. Random amplified polymorphic DNA analysis of Trypanosoma cruzi strains. Mol Biochem Parasitol 60: 71-79.

Toledo A, Martin-Sanchez J, Pesson B, Sanchiz-Marin C, MorillasMarquez F 2002. Genetic variability within the species Leish- 
mania infantum by RAPD. A lack of correlation with zymodeme structure. Mol Biochem Parasitol 119: 257-264.

Van de Peer Y, De Wachter R 1994. TREECON for Windows: a software package for the construction and drawing of evolutionary trees for the Microsoft Windows environment. Comput Appl Biosci 10: 569-570.

Volpini AC, Passos VM, Oliveira GC, Romanha AJ 2004. PCR-RFLP to identify Leishmania (Viannia) braziliensis and L. (Leishma- nia) amazonensis causing American cutaneous leishmaniasis. Acta Trop 90: 31-37.

Zemanova E, Jirku M, Mauricio IL, Miles MA, Lukes J 2004. Genetic polymorphism within the Leishmania donovani complex: correlation with geographic origin. Am J Trop Med Hyg 70: 613-617.

Zietkiewicz E, Rafalski A, Labuda D 1994. Genome fingerprinting by simple sequence repeat (SSR)-anchored polymerase chain reaction amplification. Genomics 20: 176-183. 
A
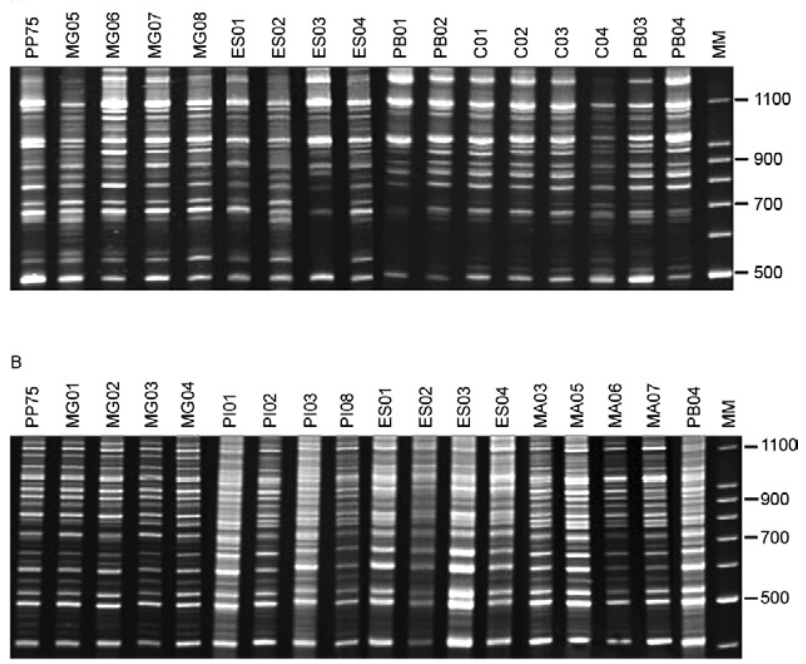

A: random amplification of polymorphic DNA profiles of Leishmania infantum isolates obtained with primer R15; B: simple sequence repeatspolymerase chain reaction profiles of $L$. infantum isolates obtained with primer $(\mathrm{CA})_{8} \mathrm{RY}$; MM: molecular weight markers of $100 \mathrm{pb}\left(\mathrm{Promega}^{\circledR}\right)$. L. infantum isolates are identified by the laboratory code reported in Table I. 